\title{
Opposing needling promotes behavior recovery and exerts neuroprotection via the CAMP/PKA/CREB signal transduction pathway in transient MCAO rats
}

\author{
YIJING JIANG $^{1 *}$, SHANLI YANG $^{1 *}$, JING TAO ${ }^{2}$, ZHICHENG LIN $^{1}$, XIAOQIAN YE ${ }^{2}$, \\ YONGMEI YOU ${ }^{2}, \mathrm{JUN} \mathrm{PENG}^{2}, \mathrm{ZHENFENG} \mathrm{HONG}^{2}$ and LIDIAN CHEN ${ }^{2}$ \\ ${ }^{1}$ Department of Rehabilitation Medicine, Rehabilitation Hospital, Fujian University of Traditional Chinese Medicine, \\ Fuzhou, Fujian 350001; ${ }^{2}$ College of Rehabilitation Medicine, Fujian University of Traditional Chinese Medicine, \\ Fuzhou, Fujian 350122, P.R. China
}

Received February 4, 2015; Accepted October 28, 2015

DOI: $10.3892 / \mathrm{mmr} .2016 .4773$

\begin{abstract}
The aim of the present study was to investigate whether the cyclic adenosine 3',5'-monophosphate (cAMP)/protein kinase A(PKA)/cAMP-responsive element binding protein (CREB) signal transduction pathway triggered by $\gamma$-aminobutyric acid class $\mathrm{B}\left(\mathrm{GABA}_{\mathrm{B}}\right)$ receptor activation is involved in neuroprotection against ischemia and behavioral recovery induced by opposing needling $(\mathrm{ON})$. A total of 80 rats were randomly divided into four groups: A sham operation group, an ischemia group, an $\mathrm{ON}$ group and an $\mathrm{ON}$ group effectively inhibited by the $\mathrm{GABA}_{\mathrm{B}}$ receptor antagonist, CGP35384 (n=20/group). The behavior of the rats was assessed by their neurological deficit score, whereas the impairment of gait was examined using the CatWalk system. The volume of cerebral infarction was examined upon treatment with 2,3,5-triphenyltetrazolium chloride. The expression levels of $\mathrm{CREB}, \mathrm{GABA}_{\mathrm{B} 1}$ and $\mathrm{GABA}_{\mathrm{B} 2}$ were examined by western blotting and reverse transcription-quantitative polymerase chain reaction, and the activity of adenylyl cyclase (AC), cAMP and PKA in the serum was detected using an enzyme-linked immunosorbent assay. In the present study, in comparison with other groups, the ON group exhibited a reduced score for the neurological deficit, the stride length and swing speed were improved, and the volume of infarction was reduced. However, these effects were reversed upon administration of CGP35384. Additionally, the expression levels of CREB, $\mathrm{GABA}_{\mathrm{B} 1}$ and
\end{abstract}

Correspondence to: Professor Lidian Chen, College of Rehabilitation Medicine, Fujian University of Traditional Chinese Medicine, 1 Qiuyang Road, Minhou Shangjie, Fuzhou, Fujian 350122, P.R. China E-mail: cld@fjtcm.edu.cn

*Contributed equally

Key words: cAMP-PKA-CREB signaling pathway, Catwalk system, focal cerebral ischemia/reperfusion, $\mathrm{GABA}_{\mathrm{B}}$ receptors, opposing needling
$\mathrm{GABA}_{\mathrm{B} 2}$ were increased in the $\mathrm{ON}$ group. The levels of $\mathrm{AC}$, cAMP and PKA in the serum were also increased in the ON group, whereas the addition of CGP35384 reversed these effects. The results of the present study demonstrated that ON markedly protected the brain against transient cerebral ischemic injury, and this effect was possibly mediated by the activation of the $\mathrm{GABA}_{\mathrm{B}} / \mathrm{cAMP} / \mathrm{PKA} / \mathrm{CREB}$ signal transduction pathway. These findings implied that ON may be a potential therapeutic method for treating stroke.

\section{Introduction}

In the United States, an improved regulation of the vascular risk factors associated with strokes, together with advances made in acute stroke care, have contributed towards a decline in the stroke mortality rate, such that strokes have fallen from third to fourth position in the leading causes of mortality (1). The age-adjusted mortality rate from strokes declined from 60.9 per 100,000 to 36.9 per $100,000(2,3)$. However, in spite of this decline in the stroke mortality rate, strokes remain a leading cause of serious long-term disability in the United States (4). The total direct annual stroke-associated medical costs are expected to increase from $\$ 71.55$ billion to $\$ 183.13$ billion between 2012 and 2030 (5). By contrast, strokes are the leading cause of mortality in China (6), which, in comparison with the world average, has a higher stroke mortality rate (126.1/100,000 higher), a greater number of years of life lost (614/100,000 higher), and a greater number of disability-adjusted life years (618/100,000 higher) (7), thereby imposing a heavy burden on patients and their families. The Chinese government has been taking several measures to prevent strokes and provide improved stroke care (8). Although a larger number of patients are surviving following a stroke, the burden of post-stroke disability is becoming increasingly important as a priority for public health (9).

Opposing needling $(\mathrm{ON})$ is an important ancient acupuncture technique, comprising the selection of acupuncture points contralateral to the diseased side. $\mathrm{ON}$ has been used to treat patients with stroke in China for a long time (10). A body of accumulating evidence from clinical trials and experimental 
research revealed that $\mathrm{ON}$ exerts protective effects against ischemic injury and is able to improve motor function $(11,12)$. However, the targets of $\mathrm{ON}$ and the underlying mechanism remain to be fully elucidated.

Following a stroke, the release of excitatory amino acids, including glutamate, exerts a key role in mediating excitotoxic neuronal damage (13), which consequently affects post-stroke rehabilitation. $\gamma$-Aminobutyric acid (GABA) is the most important inhibitory neurotransmitter in the mammalian central nervous system, which may reverse the excitotoxic neuronal damage. A total of $\sim 30 \%$ neurons in the brain produce $\mathrm{GABA}$, and almost every neuron is able to respond to GABA (14). GABA class A, B and $\mathrm{C}\left(\mathrm{GABA}_{\mathrm{A}}, \mathrm{GABA}_{\mathrm{B}}\right.$ and $\mathrm{GABA}_{C}$ ) receptors are the three types of receptor which have been identified, and $\mathrm{GABA}_{\mathrm{B}}$ receptors are G-protein- coupled receptors composed of the receptor subclasses $\mathrm{GABA}_{\mathrm{B} 1}$ and $\mathrm{GABA}_{\mathrm{B} 2}$ (15), which act presynaptically and postsynaptically. $\mathrm{GABA}_{\mathrm{B}}$ receptors have been widely used in the treatment of neurological and psychiatric disorders $(16,17)$. A number of previous studies demonstrated that enhancing the activity of $\mathrm{GABA}_{\mathrm{B}}$ receptors exerted neuroprotection against cerebral ischemia injury $(18,19)$. In addition, the underlying mechanism may be associated with the adenylyl cylcase (AC)/cyclic AMP (cAMP)/protein kinase A (PKA)/cAMP responsive element-binding protein (CREB) signal transduction pathway, and a our previous study determined that $\mathrm{ON}$ is able to increase the levels of cAMP and PKA (20). cAMP acts a secondary messenger, which is generated by the action of transmembrane-bound enzyme $\mathrm{AC}$ and is able to activate PKA. CREB in the nucleus is phosphorylated and activated by PKA, and consequently binds to the cAMP response element of target genes, which are considered to be involved in the recovery of motor function and in neuroprotection against ischemia.

The aims of the present study were: (i) To observe the effects of $\mathrm{ON}$ on gait impairment in transient middle cerebral artery occlusion (MCAO) rats; (ii) to identify whether the $\mathrm{cAMP} / \mathrm{PKA} / \mathrm{CREB}$ signal transduction pathway and the $\mathrm{GABA}_{\mathrm{B}}$ receptors were involved in neuroprotection against ischemia and motor function recovery induced by ON.

\section{Materials and methods}

Animals. Sprague-Dawley rats were reported to develop ischemic damage faster compared with Wistar-Kyoto rats, and they also develop larger ischemic lesions compared with Wistar rats in the MCAO model (21). Adult male Sprague-Dawley rats $(\mathrm{n}=80$ ) weighing 250-280 $\mathrm{g}$ were obtained from the Shanghai SLAC Laboratory Animal Co., Ltd. (Shanghai, China). The rats were caged with a standard day and night cycle $(12 \mathrm{~h} / 12 \mathrm{~h})$ in a temperature-controlled environment $\left(21 \pm 2^{\circ} \mathrm{C}\right)$. The relative humidity level was $55 \pm 5 \%$, and the animals were provided with adequate food and water. After 7 days of adaptation to the experimental conditions, the rats were randomly divided into the sham-operation (SC) group, the ischemia (IS) group, the ON group and the ON + CGP35384 group (n=20/group). This study was approved by the ethics committee of the Fujian University of Traditional Chinese Medicine (Fuzhou, China). All animal procedures were performed in accordance with the Institutional Animal Care and Use Committee of the Fujian
University of Traditional Chinese Medicine. All efforts were made to minimize the number of animals used in the present study and the suffering of animals.

Transient MCAO. Rats in the IS, ONand ON + CGP35384 groups were subjected to MCAO surgery, as previously described (22), with minor modifications. Briefly, the rats were anesthetized with $10 \%$ chloral hydrate $(250 \mathrm{mg} / \mathrm{kg}$; Wuhan Hechang Chemical Co., Ltd., Wuhan, China) by intraperitoneal injection. A 2-2.5 cm incision was made in the centre of the neck. The left common carotid artery, the external carotid artery and the internal carotid artery (ICA) were exposed and isolated. A heparinized nylon filament (diameter $0.26 \mathrm{~mm}$ ) was gently introduced into the ICA in order to block the origin of the left middle cerebral artery. The incision was subsequently ligatured and sutured. Gentamicin sulphate was administered to prevent postoperative infections or dehydration following surgery. Reperfusion was induced $2 \mathrm{~h}$ following the MCAO surgery using the filament withdrawal technique (23). The SC group received the identical surgical procedure without placing the filament into the ICA. The rectum temperature of the rats was maintained at $37 \pm 1^{\circ} \mathrm{C}$ during the surgery using a heating pad. The extent of neurological impairment was assessed 1 day following the MCAO surgery by determining the neurological deficit score (22) in order to confirm a successful occlusion. Animals exhibiting no behavioral impairment were excluded from the study and no postoperative mortality occurred.

Behavioral measurements. A five-point scale (0-4) was employed for the neurological deficit score, and each point was characterized by the following attributes: 0 , no neurological deficit observed; 1 , mild focal neurological deficit, presented by a failure to extend the left forepaw fully; 2, a moderate focal neurological deficit, presented by circling to the left; 3 , a severe focal deficit, presented by an inability to bear weight on the left; 4, an inability to walk spontaneously, with a depressed level of consciousness. Neurological evaluation was performed by assessing the neurological deficit score (22) on days 1, 2 and 7 following the MCAO surgery.

For the Catwalk test, a CatWalk XT 10.0 system (Noldus Information Technology, Wageningen, The Netherlands) was used. The CatWalk XT 10.0 system is a video-based, advanced gait analysis system designed to dynamically measure the footprints of voluntarily moving animals and to assess any locomotor deficits and the pain syndrome in animal models $(24,25)$, which is widely used in experimental stroke studies $(26,27)$. It is considered to be a useful tool for studying motor impairment in stroke animals (28). The 'Catwalk' apparatus consisted of a plexglass walkway, fluorescent lights, a video camera and CatWalk software. The operational principle of CatWalk was a walkway made of plexiglass, on which the rats traversed from one side of the glass plate to the other, and the entire walkway was illuminated and completely internally reflected by fluorescent lights. Since the light was restricted to the plexiglass walkway, light was able to escape only at those areas where the animal made a contact with the plexiglass walkway (typically, the animal's paws). Therefore, the manner in which the animal ran across the walkway was detected by a video camera mounted underneath the walkway, and by means of capturing the illuminated areas, the video images 
Table I. Explanation of the Catwalk parameter.

Paw parameter

Explanation

Stance duration (sec)

Stride length $(\mathrm{cm})$

Maximum contact area $\left(\mathrm{cm}^{2}\right)$

Swing speed $(\mathrm{cm} / \mathrm{sec})$

Swing duration (sec)
The speed between two consecutive initial contacts of the same paw: stand + swing The amount of light reflected by a paw as an indirect measure of weight bearing The total floor area contacted by the paw

The speed of the paw during the swing phase

The distance between either the front or the hind paws were transmitted to the connected computer. Subsequently, all the data were acquired, compressed, stored and eventually analyzed using the CatWalk software program.

Prior to the first test, the rats were trained for 2 days to acclimatize to the walkway environment. The home cages of the rats were placed at one side of the walkway, and the rats were placed at the opposite side. The rats were trained to make consecutive runs over the walkway towards their home cages, without any interruption. Food was used as a reward during the rats' training. A trial was considered to be successful if rats were able to transverse the walkway without interruption within a duration of $10 \mathrm{sec}$. Any unsuccessful trial (marked by the animal stopping on the walkway, walking backwards or rearing during the run) was repeated, until the required number of trials was achieved. The camera recorded three consecutive complete runs across the walkway. The average of three trials was taken for subsequent statistical analysis, as performed using the Catwalk XT 10.0 Software. An experienced researcher labeled each paw on the recorded video, in a blinded manner, and the paw-associated parameters were reported. Descriptions of the gait-associated parameters (25), as measured using the CatWalk system, were defined, as shown in Table I. The gait of the rats was assessed on days 1 and 7 following the surgery. All rats in the present study were able to accomplish the Catwalk task.

Animal grouping and intervention. A total of 80 rats were randomized into four groups (the SC, IS, ON and ON + CGP35384 groups; $n=20 /$ group). The rats in the IS, $\mathrm{ON}$ and $\mathrm{ON}+\mathrm{CGP} 35384$ groups were subjected to transient MCAO surgery. The IS and SC groups served as no-intervention controls for the $\mathrm{ON}$ group. The rats in the $\mathrm{ON}$ and $\mathrm{ON}+\mathrm{CGP} 35384$ groups received electroacupuncture treatment for $30 \mathrm{~min}$ daily over a continuous period of 7 days. For each session, acupuncture was applied bilaterally. The Hegu (LI4), Waiguan (TE5), Yanglingquan (GB34) and Zusanli (ST36) acupuncture points were punctured perpendicularly at intervals of 2-3 mm. Subsequently, four auxiliary needles were punctured at $2 \mathrm{~mm}$ intervals lateral to each acupuncture point. Two types of Hwato disposable steel needle (Suzhou Hua Tuo Medical Instruments, Suzhou, China) were used (length, 25, diameter, $0.25 \mathrm{~mm}$ and length, 13, diameter, $0.18 \mathrm{~mm}$ ), and transcutaneous electric acupoint stimulation (HANS; Han's acupoints nerve stimulator, HANS-200, Nanjing, China) was applied to stimulate the acupoints for $30 \mathrm{~min}$ at a frequency of 1-20 Hz. For the ON + CGP35384 group, the $\mathrm{GABA}_{\mathrm{B}}$ receptor antagonist, CGP35384 (1 mg/ml solvent/kg body weight; Wuhan Hechang Chemical Co., Ltd.), was injected intraperito- neally $30 \mathrm{~min}$ prior to the surgery to inhibit $\mathrm{GABA}_{\mathrm{B}}$ receptor activation (29). All rats were sacrificed by decapitation 7 days following the MCAO surgery for subsequent cerebral infarct volume, western blot analysis and reverse transcription-quantitative polymerase chain reaction (RT-qPCR). The experimental protocols are illustrated in Fig. 1.

Infarct volume measurement. The infarct volumes were measured using 2,3,5-triphenyltetrazolium chloride (TTC) staining (30). On day 7 following MCAO surgery, all the rats were deeply anesthetized and decapitated. The brains were swiftly removed, snap-frozen and stored at $-20^{\circ} \mathrm{C}$ for $30 \mathrm{~min}$. The brains were sectioned into six $2 \mathrm{~mm}$-thick slices. All slices were stained with $1 \%$ TTC phosphate buffer solution (pH 7.4) and incubated at $37^{\circ} \mathrm{C}$ for $15 \mathrm{~min}$ in order to optimize the TTC staining. Subsequently, the slices were transferred to $12 \%$ formalin solution for fixation for $2 \mathrm{~min}$. Finally, images of the TTC-stained slices were captured using an Olympus FE-240 digital camera (Shanghai Pooher Photoelectric Technology Co., Ltd., Shanghai, China) and analyzed using ImagePro ${ }^{\circledR}$ Plus 6.0 analysis software (Media Cybernetics, Inc., Rockville, MD, USA). The infarction volume was expressed as the infarction ratio (a percentage of the total ipsilateral hemispheric volume), which was calculated according to the following equation $(31,32)$ : [(contralateral hemispheric volume - ipsilateral hemispheric volume)/contralateral hemispheric volume] x $100 \%$.

Western blot analysis. The left cortex surrounding the infarct was isolated prior to homogenization in radioimmunoprecipitation buffer (Beyotime Institute of Biotechnology, Shanghai, China), containing a protease inhibitor cocktail (Beyotime Institute of Biotechnology), and centrifugation at 15,984 x g for $20 \mathrm{~min}$ at $4^{\circ} \mathrm{C}$. The supernatants were collected and the protein concentration was determined using a bicinchoninic acid kit (Beyotime Institute of Biotechnology); the absorbance was measured using an automatic enzyme instrument (ELx800; Biotek Instruments, Inc., Winooski, VT, USA). Subsequently, the proteins were separated using $12 \%$ sodium dodecyl sulfate-polyacrylamide gel electrophoresis (Beyotime Institute of Biotechnology) and transferred onto polyvinylidene difluoride membranes (EMD Millipore, Billerica, MA, USA). Following $1 \mathrm{~h}$ of blocking with $5 \%$ non-fat dry milk in Tris-buffered saline, the membranes were incubated with the following primary antibodies: Anti-CREB (1:1,000; cat. no. 9197S; Cell Signaling Technology, Inc., Danvers, MA, USA) anti-GABA ${ }_{\mathrm{B} 1}\left(1: 1,000\right.$; cat. no. ab55051) and $\mathrm{GABA}_{\mathrm{B} 2}$ (1:1,000; cat. no. ab75838) (Abcam, Cambridge, UK) overnight 
at $4^{\circ} \mathrm{C}$. Following incubation with the primary antibody, the membranes were rinsed and incubated with the horseradish peroxidase-conjugated secondary antibody (1:2,000; cat. no. A0545-1ML; Sigma-Aldrich, St. Louis, MO, USA). The protein bands were visualized using an enhanced chemiluminescence kit (Santa Cruz Biotechnology, Inc., Santa Cruz, CA, USA), and the levels of protein present were analyzed using the integral optical density detection technique (QuantityOne ${ }^{\circledR}$ software; Bio-Rad, Hercules, CA, USA) and normalized against $\beta$-actin $(1: 1,000$; cat. no. 4970S; Cell Signaling Technology, Inc.) as the control.

$R T$ - $q P C R$. The left cortex surrounding the infarct was dissected and frozen at $-80^{\circ} \mathrm{C}$. RNA isolation was performed using standard procedures (33) and Invitrogen TRIzol ${ }^{\circledR}$ reagent (Thermo Fisher Scientific, Inc., Waltham, MA, USA). The total RNA was run on a $2 \%$ agarose gel and quantified by densitometric analysis using the Fluor-S MultiImager ${ }^{\circledR}$ imaging system (Bio-Rad Laboratories, Milan, Italy). The total RNA $(1 \mu \mathrm{g})$ was reverse-transcribed using the first-strand synthesis system for RT-qPCR (Invitrogen SuperScript ${ }^{\circledR}$; Thermo Fisher Scientific, Inc.) in a final volume of $20 \mu \mathrm{l}$ for $1 \mathrm{~h}$ at $42^{\circ} \mathrm{C}$, according to the manufacturer's protocol. RT-qPCR was performed in a Real-Time PCR detector using the SYBR Green real-time PCR Master mix (Toyobo Co., Ltd., Osaka, Japan), according to the manufacturer's protocol. Specific primers were designed for the rat $\mathrm{GABA}_{\mathrm{B} 1}, \mathrm{GABA}_{\mathrm{B} 2}, \mathrm{CREB}$ and glyceraldehyde- 3- phosphate dehydrogenase (GAPDH) genes, as shown in Table II. The basic protocol used for the qPCR analysis was an initial denaturation at $95^{\circ} \mathrm{C}$ for $10 \mathrm{~min}$, followed by 45 cycles of amplification. For the cDNA amplification, the cycles consisted of denaturation at $95^{\circ} \mathrm{C}$ for $10 \mathrm{~min}$, annealing at $95^{\circ} \mathrm{C}$ for $15 \mathrm{sec}$ and elongation at $60^{\circ} \mathrm{C}$ for $60 \mathrm{sec}$. The SYBR green signal was detected using the iQ5 real-time PCR detection system (Bio-Rad). The PCR products were analyzed using gel electrophoresis, and melting curve analysis was used to confirm the specificity of the amplifications. The mRNA expression levels were normalized against that of the housekeeping gene, GAPDH, and the levels of the transcripts were quantified using the $2^{-\Delta \Delta \mathrm{Cq}}$ method (34).

Enzyme-linked immunosorbent assay (ELISA) for AC, $c A M P$ and $P K A$. Blood was obtained from the abdominal aorta of the rats using a hemospast, prior to centrifugation at $1,000 \mathrm{x} \mathrm{g}$ for $10 \mathrm{~min}$ at $4^{\circ} \mathrm{C}$. The serum was subsequently collected and stored at $-80^{\circ} \mathrm{C}$ prior to assaying. The titers of AC, cAMP and PKA were measured using ELISA, and the results were expressed as optical density (OD) units, according to previously published methods (35). Briefly, the plates were coated with the capture antibody overnight at $4^{\circ} \mathrm{C}$, following washing with $0.05 \%$ Tween 20 in phosphate buffered saline. The standards and samples were added prior to incubation in the coated plates at room temperature for $2 \mathrm{~h}$. The plates were subsequently washed, and the detection antibody was added and incubated for $1 \mathrm{~h}$, prior to a subsequently washing step. Streptavidin-horseradish peroxidase-conjugated antibody was added at room temperature for an incubation of $1 \mathrm{~h}$. Subsequently, tetramethylbenzidine substrate solution (Clinical Science Products, Inc., Mansfield, MA, USA) was added to produce a blue-colored solution. The enzyme
Table II. Nucleotide sequences of the primers used for real-time PCR.

\begin{tabular}{|c|c|}
\hline Gene & Primer \\
\hline $\mathrm{GABA}_{\mathrm{B} 1}$ & $\begin{array}{l}\text { Forward: 5'- CAGACACGTAGATCCTCCGC-3' } \\
\text { Reverse: 5'-CGTACGCGTATACCAAGGCT-3' }\end{array}$ \\
\hline $\mathrm{GABA}_{\mathrm{B} 2}$ & $\begin{array}{l}\text { Forward: 5'-GGAAACCCGCAATGTGAGC-3' } \\
\text { Reverse: 5'-GGCACAAACACCAGGCAFAG-3' }\end{array}$ \\
\hline CREB & $\begin{array}{l}\text { Forward: 5'-AAGAATATGGCTCCGATTGC-3' } \\
\text { Reverse:5'-TGAGGATCTCATGGTAAACAGC-3' }\end{array}$ \\
\hline GAPDH & $\begin{array}{l}\text { Forward: 5'-GGCAAGTTCAACGGCACAG-3' } \\
\text { Reverse: 5'-CGCCAGTAGACTCCACGAC-3' }\end{array}$ \\
\hline
\end{tabular}

CREB, cAMP-responsive element binding protein; GAPDH, glyceraldehyde- 3- phosphate dehydrogenase; GABA, $\gamma$-aminobutyric acid.

substrate reaction was stopped by the addition of sulfuric acid $\left(\mathrm{H}_{2} \mathrm{SO}_{4}\right)$, with the solution thereby turning yellow. The OD of each well was immediately determined using a microplate reader (Bio-Rad) set at $450 \mathrm{~nm}$.

Statistical analysis. All data are continuous and are expressed as the mean \pm standard deviation. Within-group and between-group differences were detected using analysis of co-variance (ANCOVA), which was adjusted for baseline parameters. A post-hoc analysis of ANCOVA was performed using Tukey's test and $\mathrm{P}<0.05$ was considered to indicate a statistically significant difference. R software (version 3.1.1; http://www.r-project.org/) was used to conduct statistical analyses.

\section{Results}

ON acupuncture reduced the score of the neurological deficit. The neurological score is a 5 point scale, in which a higher score indicated a higher loss of neurological function. The rats in the IS group exhibited an increased neurological score 1 day following ischemia-reperfusion (IR; $2.83 \pm 0.39$ ), which indicated a successful implementation of the MCAO model (Fig. 2). The score was not significantly reduced on days 2 and 7 following IR $(2.58 \pm 0.36$ and $2.50 \pm 0.37$, respectively), indicating no marked improvement in the animals' condition. However, the ON acupuncture treatment significantly reduced the neurological deficit score on day 2 following IR $(1.54 \pm 0.49$, compared with 1 day following IR; $\mathrm{P}<0.05)$, and also on day 7 following IR $(1.08 \pm 0.19$, compared with 1 day following IR; $\mathrm{P}<0.05)$. However, this effect was reversed by administering the antagonist, CGP35384, prior to the acupuncture. A small, although insignificant reduction of the neurological deficit score was observed ( 1 day following IR, 2.67 $\pm 0.40 ; 2$ days following IR, 2.13 \pm 0.48 ; 7 days following IR, 2.25 \pm 0.42 ). A significant difference among the groups was identified: The ON group exhibited a lower score compared with the IS and the ON + CGP35384 groups $(\mathrm{P}<0.05)$. Further details are shown in Fig. 2. 


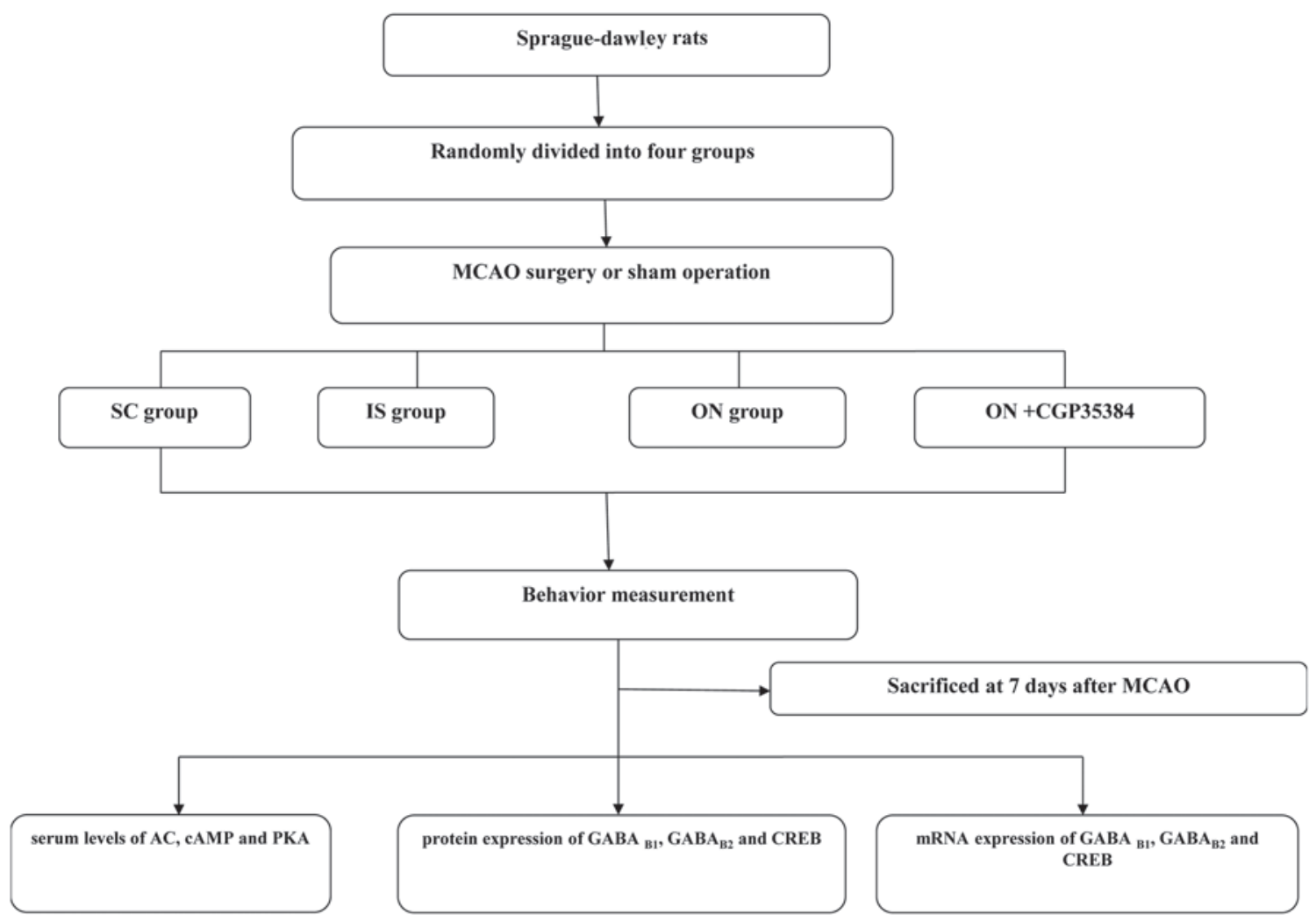

Figure 1. A flow chart illustrating the experimental procedures employed in the present study. A total of 80 adult Sprague-dawley rats were randomly divided into the SC, IS, ON and ON + CGP35384 groups. The behavior of the rats was assessed, and the animals were subsequently sacrificed at 7 days following MCAO surgery or the sham operation prior to enzyme-linked immunosorbent assay, western blotting and reverse transcription-quantitative polymerase chain reaction analysis. SC, sham-operation; IS, ischemia; ON, opposing needling; MCAO, middle cerebral artery occlusion; AC, adenylyl cyclase; cAMP, cyclic adenosine 3',5'-monophosphate; GABA, $\gamma$-aminobutyric acid; PKA, protein kinase A; CREB, cAMP-responsive element binding protein.

ON acupuncture improves the total score of the Catwalk system. The Catwalk system was used to assess the gait performance. At day 1, the maximum contact area and stance duration were significantly decreased in the right forepaw (RF; IS, vs. SC group, 0.64 , vs. 0.74 and 0.38 , vs. 0.60 , respectively; Table III) Following ON therapy, at day 7, the stride length and swing speed were significantly improved in the (RF; ON, vs. IS group, 7.23 , vs. $6.09,39.82$, vs. 32.1, respectively). This effect was partly reversed by the antagonist for the stride length in the RF (ON, vs. ON + CGP35384 group, 7.23, vs. 6.12). Similar results were identified with respect to the right hindpaw, as shown in Table III.

ON acupuncture decreased the infarct sizes of the rats' brains. The infarct sizes of the rat brains were measured at 7 days following the MCAO surgery; a small size indicated an improved outcome. The rats in the IS group showed a significantly higher infarct size compared with those in the SC group (mean infarct size, 34.23 , vs. $0 ; \mathrm{P}<0.001$; Fig. 3). The $\mathrm{ON}$ acupuncture reduced the infarct size following MCAO surgery (mean infarct size for the ON, vs. the IS group, 18.35, vs. 34.23; $\mathrm{P}<0.001)$; however, this effect was reversed when the $\mathrm{GABA}_{\mathrm{B}}$ antagonist, CGP35384, was administered prior to the ON acupuncture (mean infarct size for the ON + CGP35384, vs. the ON group, 37.82 , vs. 18.35 ; $\mathrm{P}<0.001$; Fig. 3).

$O N$ acupuncture increased the protein and $M R N A$ expression levels of $C R E B, G A B A_{B 1}$ and $G A B A_{B 2}$ in the cerebral tissue.

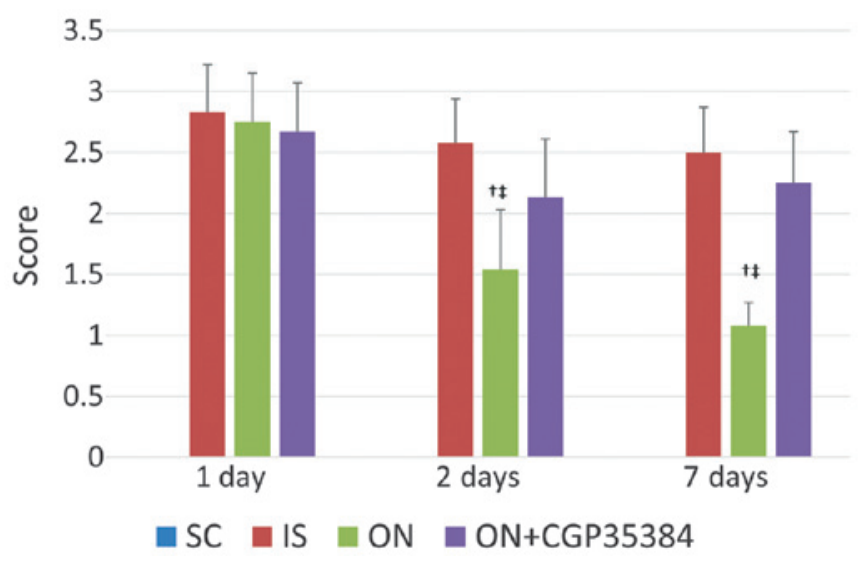

Figure 2. Results of the neurological deficit score at different days following ischemia-reperfusion. The values are expressed as the mean \pm standard deviation. ${ }^{\dagger}$ The $\mathrm{ON}$ group vs. IS group, $\mathrm{P}<0.05$. ${ }^{\ddagger}$ The $\mathrm{ON}$ group vs. $\mathrm{ON}+\mathrm{CGP} 35384$ group, $\mathrm{P}<0.05$. SC, sham- operation; IS, ischemia; ON, opposing needling.

It was hypothesized that an increased mRNA expression of the $\mathrm{GABA}_{\mathrm{B}}$ receptors would lead to a suppression of the abnormal excitation of the nervous and muscular systems, and therefore a higher level of expression of the $\mathrm{GABA}_{\mathrm{B}}$ receptors would indicate an improvement in the neurological and the motor functions. In the present study, the CREB mRNA decreased in the cerebral tissue of rats 7 days post-MCAO surgery (IS, vs. SC group, $0.23 \pm 0.09$, vs $1.08 \pm 0.18$; $\mathrm{P}<0.05$; Fig. 4). A similar decrease in mRNA expression was observed 


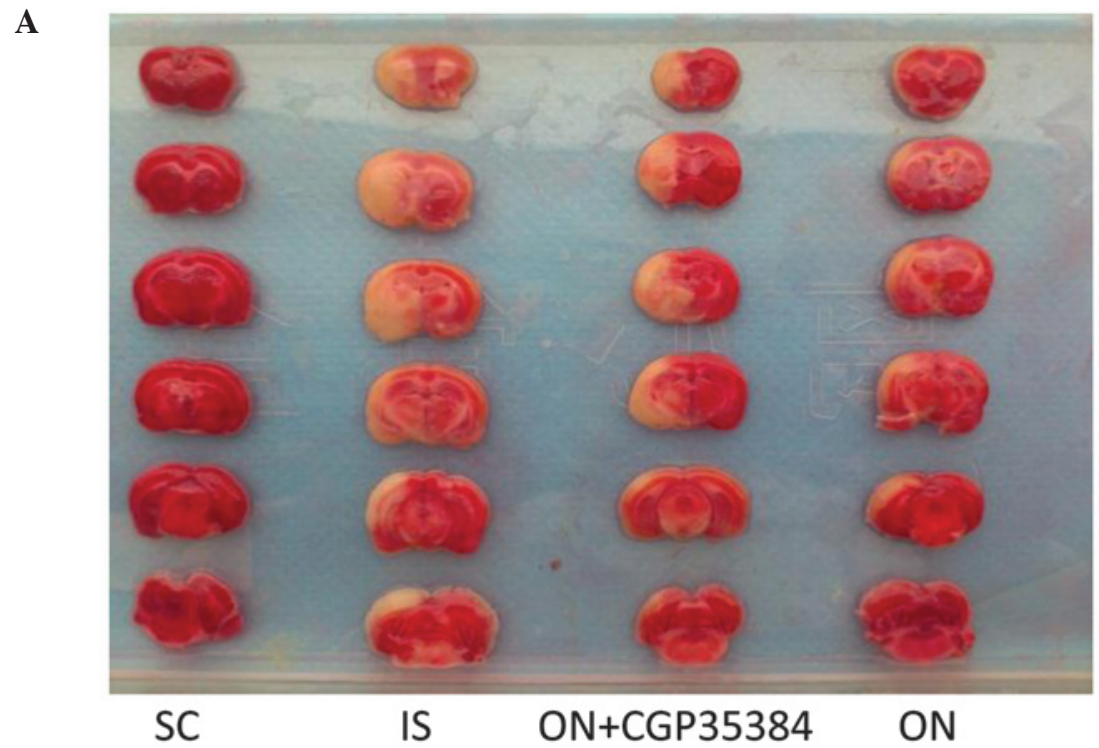

B

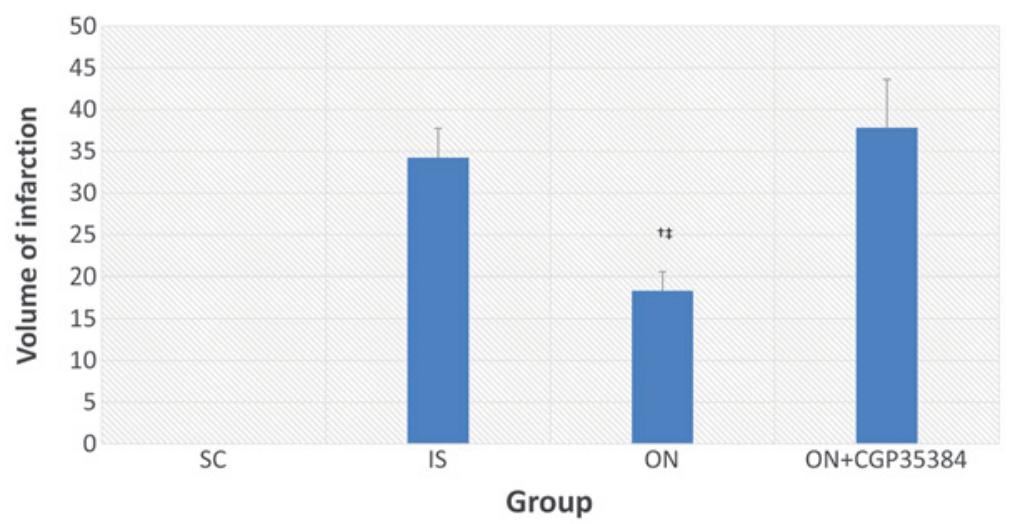

Figure 3. Effect of ON acupuncture on the infarct size of the rat brains. (A) An observation of the infarction volume for each of the four experimental groups and (B) the assessment of infarct size. The values are presented as the mean \pm standard deviation. ${ }^{\dagger}$ The ON group vs. IS group, $\mathrm{P}<0.05$; the ON group vs. $\mathrm{ON}+\mathrm{CGP} 35384$ group, $\mathrm{P}<0.05$. SC, sham-operation; IS, ischemia; ON, opposing needling.

with $\mathrm{GABA}_{\mathrm{B} 1}$ (IS, vs. SC group, $1.16 \pm 0.22$, vs. $1.90 \pm 0.32$; $\mathrm{P}<0.05)$, and a similar result was also obtained for $\mathrm{GABA}_{\mathrm{B} 2}$ (IS, vs. SC group, $1.08 \pm 0.26$, vs. $2.57 \pm 0.18$; $\mathrm{P}<0.05$ ). ON acupuncture significantly increased the mRNA expression levels of CREB, $\mathrm{GABA}_{\mathrm{B} 1}$ and $\mathrm{GABA}_{\mathrm{B} 2}(\mathrm{CREB}, 0.88 \pm 0.12$; $\left.\mathrm{GABA}_{\mathrm{B} 1}, 2.21 \pm 0.33 ; \mathrm{P}<0.001 ; \mathrm{GABA}_{\mathrm{B} 2}, 2.56 \pm 0.43, \mathrm{P}<0.001\right)$ following MCAO surgery. This effect was reversed by the antagonist, CGP35384 (CREB, 0.34 \pm 0.06 ; $\mathrm{GABA}_{\mathrm{B} 1}, 0.97 \pm 0.2$; $\left.\mathrm{P}<0.05 ; \mathrm{GABA}_{\mathrm{B} 2}, 1.16 \pm 0.33 ; \mathrm{P}<0.05\right)$. Similar results were obtained regarding the protein expression levels of CREB, $\mathrm{GABA}_{\mathrm{B} 1}$ and $\mathrm{GABA}_{\mathrm{B} 2}$, as detected by western blot analysis (Fig. 5)

$O N$ acupuncture positively regulates the AC/cAMP/PKA signaling pathway. The cAMP/PKA/CREB pathway operates downstream of the activation of the GABA receptors, which may provide the putative mechanism to account for the prevention of IR damage by the $\mathrm{ON}$ acupuncture. Following the MCAO surgery and reperfusion for 7 days, the levels of AC, cAMP and PKA in the serum were significantly reduced (IS, vs. SC group: AC, $19.21 \pm 1.9$, vs. $26.05 \pm 2.3$; cAMP, $7.98 \pm 0.89$, vs. $10.55 \pm 0.98$; PKA, $298.85 \pm 31.88$, vs. $360.48 \pm 35.43$; $\mathrm{P}<0.05$;
Fig. 6). The $\mathrm{ON}$ acupuncture significantly increased the levels of cAMP, PKA and CREB in the cerebral tissue (ON, vs. IS group: AC, $24.95 \pm 2.5$, vs. $19.21 \pm 1.9$; cAMP, $11.58 \pm 1.56$, vs. $7.98 \pm 0.89$; PKA, 387.47 \pm 29.78 , vs. $298.85 \pm 31.88$; $P<0.01)$. However, administering the antagonist, CGP35384, prior to the $\mathrm{ON}$ acupuncture reversed this effect (ON + CGP35384, vs. ON group: AC, $18.13 \pm 2.2$, vs. $24.95 \pm 2.5$; cAMP, $8.12 \pm 1.1$, vs. $11.58 \pm 1.56$; PKA, $278.66 \pm 29.85$, vs. $387.47 \pm 29.78$; P $<0.01$; Fig. 6).

\section{Discussion}

The results of the present study revealed that ON acupuncture significantly reduced the extent of cerebral infarction and improved the motor function of the MCAO rats. These findings also demonstrated that, compared with the IS group, $\mathrm{ON}$ acupuncture resulted in an increase in the protein and mRNA expression levels of CREB, $\mathrm{GABA}_{\mathrm{B} 1}$ and $\mathrm{GABA}_{\mathrm{B} 2}$. Using ELISA, it was further determined that the activity of $\mathrm{AC}$, cAMP and PKA increased in the ON group, whereas the activity of AC, cAMP and PKA decreased in the IS group. However, these effects were reversed by administering the $\mathrm{GABA}_{\mathrm{B}}$ antagonist, CGP35384. 


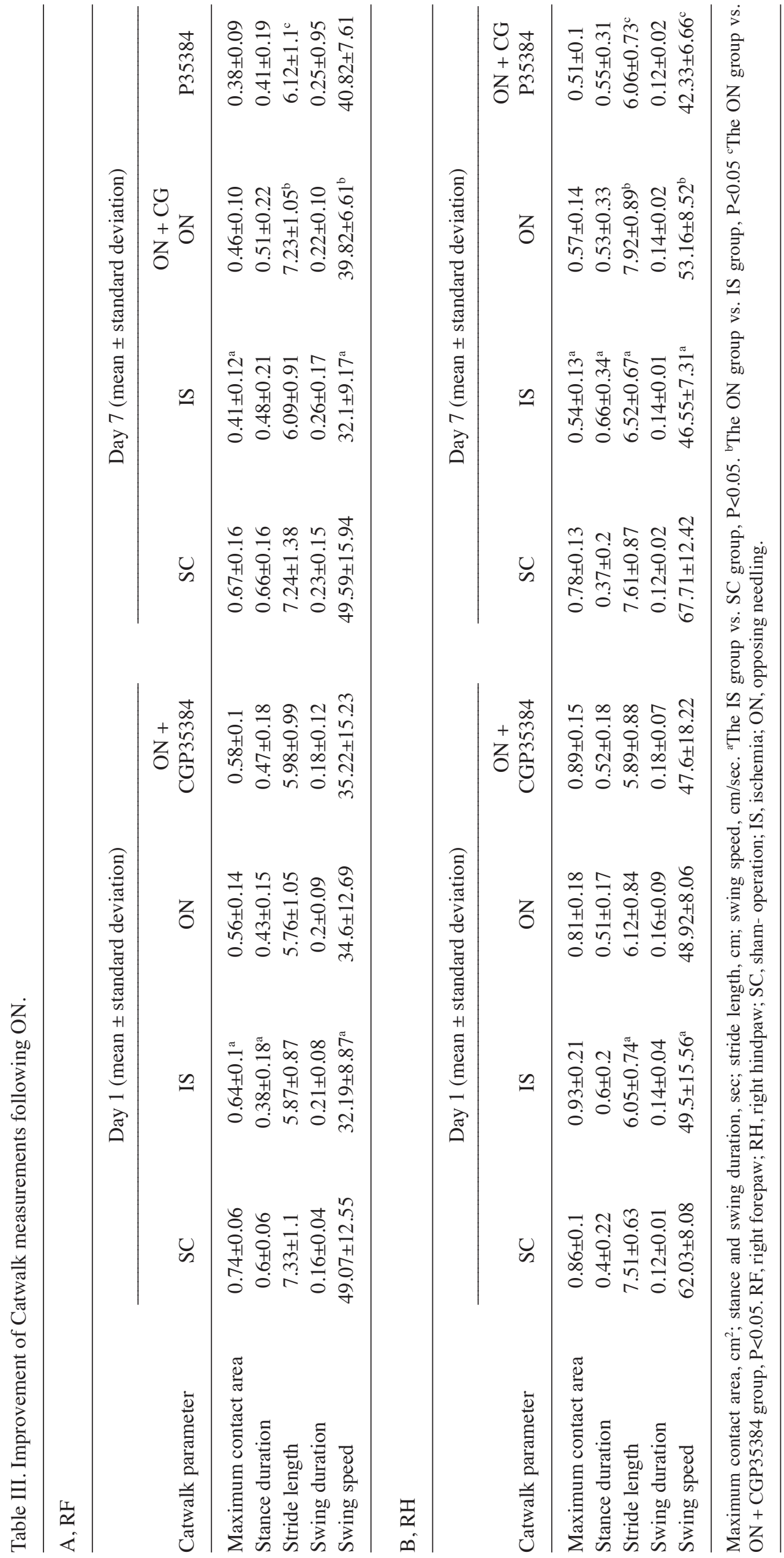



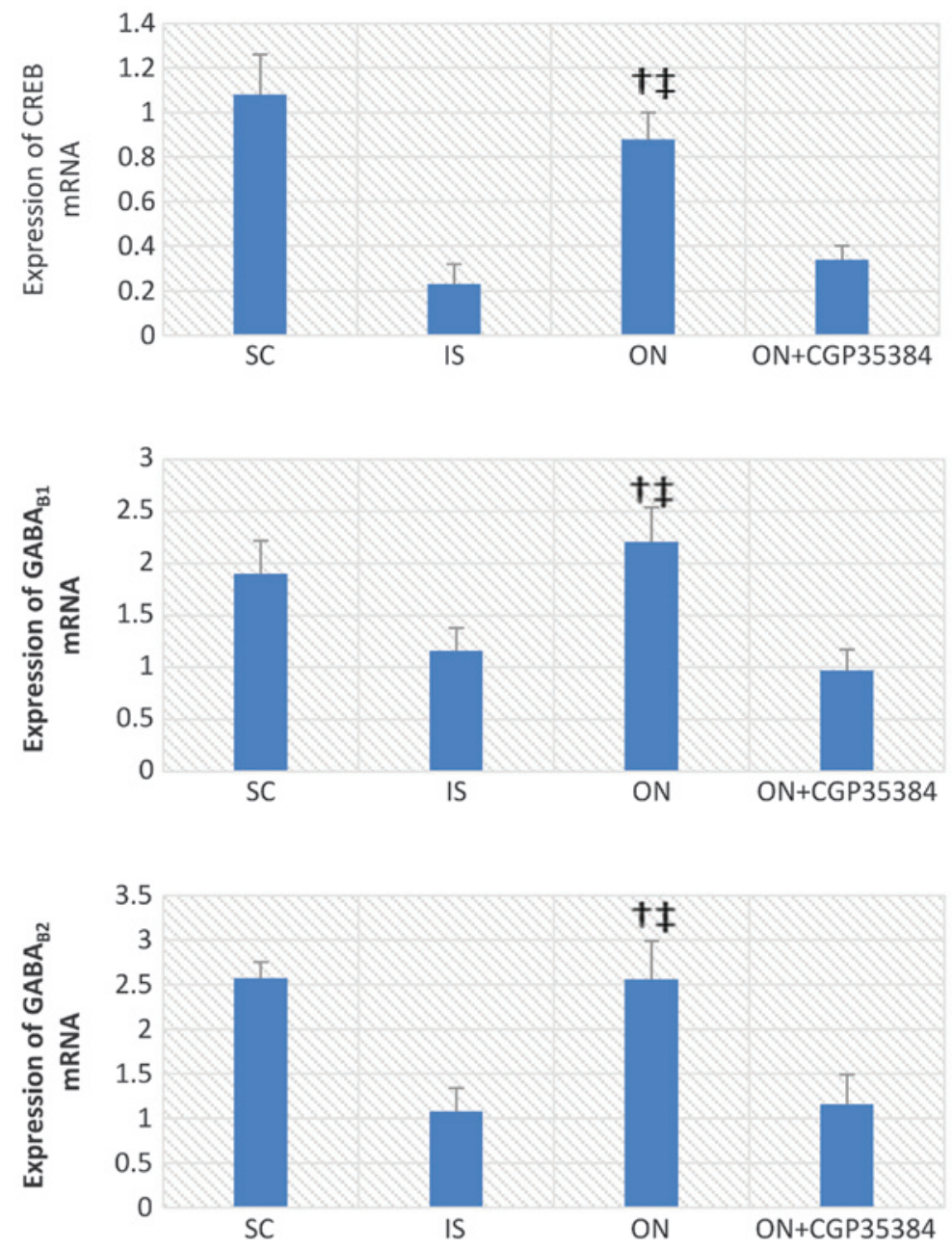

Figure 4. mRNA expression levels of CREB, $\mathrm{GABA}_{\mathrm{B} 1}$ and $\mathrm{GABA}_{\mathrm{B} 2}$ in the cerebral tissue. The data are presented as the mean \pm standard deviation. ${ }^{\prime}$ The ON group vs. the IS group, $\mathrm{P}<0.01$; ${ }^{\star}$ the $\mathrm{ON}$ group vs. the $\mathrm{ON}+\mathrm{CGP} 35384$ group, $\mathrm{P}<0.01$. SC, sham-operation; IS, ischemia; ON, opposing needling; GABA, $\gamma$-aminobutyric acid; CREB, cAMP-responsive element binding protein.

IR proceeds via the mechanisms associated with excitotoxic neurotoxicity, which, following induction by excitatory amino acids, includes the processes of intracellular $\mathrm{Ca}^{2+}$ overload, an increase in $\mathrm{Na}^{+}$influx increase and the co-transport of $\mathrm{Cl}^{-}$and water, resulting in further cytotoxic brain edema and neuronal damage $(36,37)$. However, these processes are counteracted by certain inhibitory amino acids, particularly GABA, one of the major inhibitory neurotransmitters, which is able to increase chloride conductance, diminish the effects of depolarization, open the calcium channel, and decrease the ATP consumption and cell apoptosis that is induced by cerebral ischemia (38). Therefore, increasing the inhibitory neurotransmitter activity or increasing the activity of the GABA receptor activity provides an effective means to exert neuroprotection against ischemia (39). Dave et al (40) demonstrated that increased levels of GABA release in preconditioned animals following ischemia may provide one of the factors responsible for neuroprotection. The specific activation of the $\mathrm{GABA}_{\mathrm{B}}$ receptors greatly contributes towards neuroprotection against ischemia. The present study also demonstrated that an increase in the mRNA expression levels of $\mathrm{GABA}_{\mathrm{B} 1}$ and $\mathrm{GABA}_{\mathrm{B} 2}$ was associated with improvements in the motor function and neuroprotection against IR in the MCAO rats.
It is known that the cAMP/PKA/CREB signaling pathway exerts an important role in synaptic plasticity and long-term memory formation $(41,42)$. However, a subsequent study (43) and a previous report from our laboratory (20) suggested a possible connection between the cAMP/PKA/CREB signal transduction system and neuroprotection. The previous report from our laboratory revealed that $\mathrm{ON}$ acupuncture exerted neuroprotective effects, promoted the activity of AC, cAMP and PKA, and increased the mRNA expression of CREB in the cerebral tissue (20), whereas such observations were not made in ischemic rats. Therefore, it was hypothesized that the neuroprotection afforded by ON may be mediated through the cAMP/PKA/CREB signaling pathway, and the present study was performed in an attempt to confirm this hypothesis.

In the present study, experimental evidence was provided to demonstrate that $\mathrm{ON}$ exerts a neuroprotective effect, alleviates neural functional damage and improves the gait impairment of $\mathrm{MCAO}$ rats. A previous study reported that the $\mathrm{GABA}_{\mathrm{B}}$ receptor increases $A C$ activity mediated by $\mathrm{G}_{\mathrm{i}} / \mathrm{G}_{\mathrm{o}}$ protein (44), thereby leading to an increase in the levels of cAMP. cAMP is a representative secondary messenger, which is generated by the activity of the transmembrane-bound enzyme, AC, and 
A
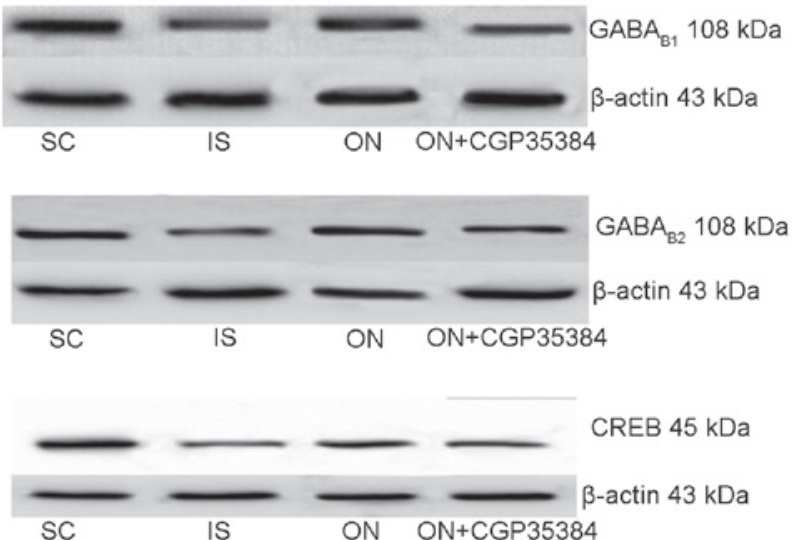

B
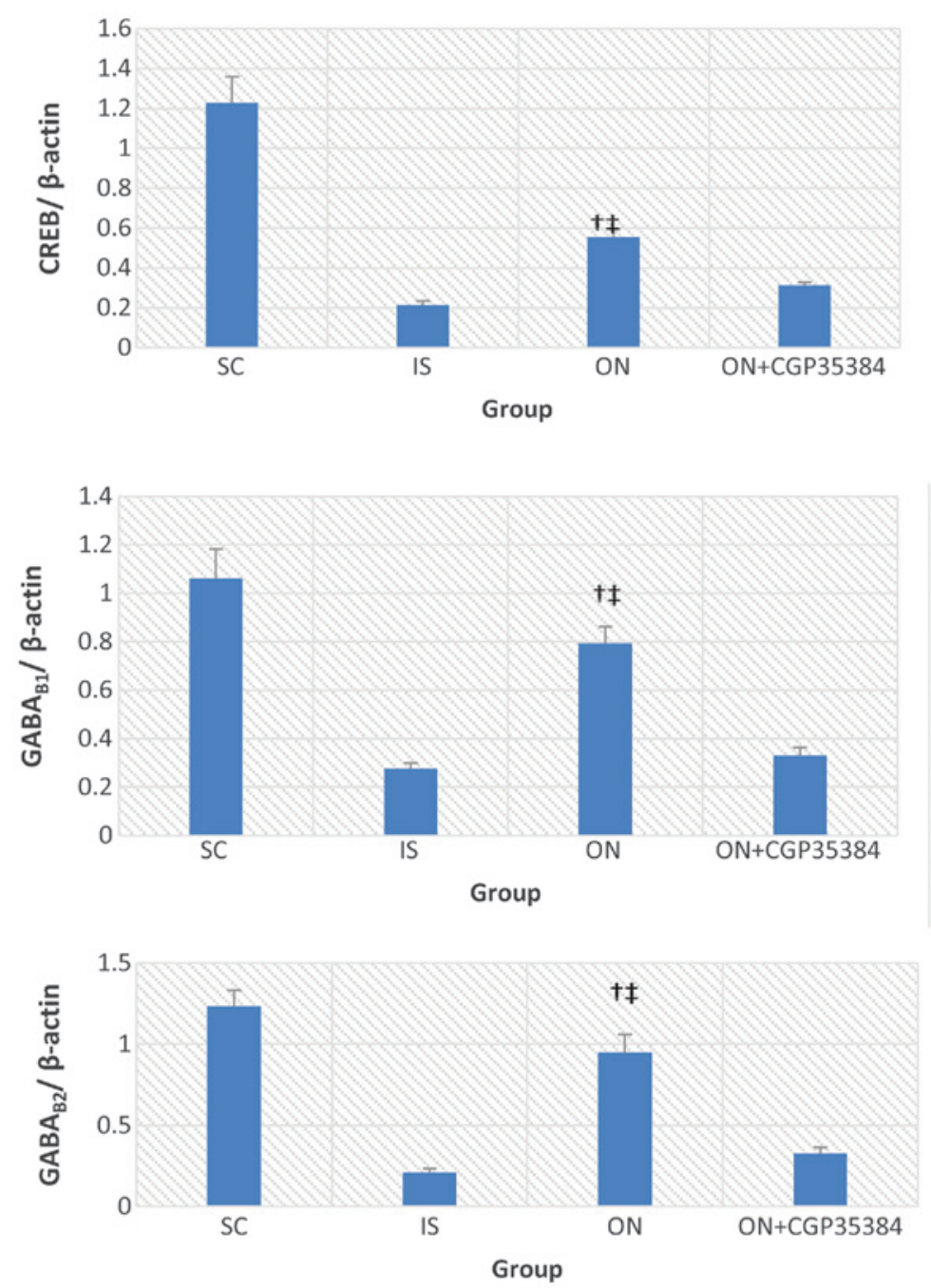

Figure 5. (A) Expression of the $\mathrm{GABA}_{\mathrm{B} 1}$ and $\mathrm{GABA}_{\mathrm{B} 2}$ proteins, as detected by western blotting. (B) The graphical representation of the intensity of the protein bands (as measured by their optical density, normalized against $\beta$-actin). The data are presented as the mean \pm standard deviation. ${ }^{\dagger}$ The ON group vs. the IS group, $\mathrm{P}<0.05$; the $\mathrm{ON}$ group vs. the $\mathrm{ON}+\mathrm{CGP} 35384$ group, $\mathrm{P}<0.05$. CREB, cAMP-responsive element binding protein; GABA, $\gamma$-aminobutyric acid; SC, sham-operation; IS, ischemia; ON, opposing needle.

which is able to activate PKA. Subsequently, CREB in the nucleus is phosphorylated and activated by PKA. CREB was shown to regulate a number of aspects of neuronal functioning, including neuronal development and synaptic plasticity. A burgeoning body of evidence suggests that CREB may also be involved in the active process of neuroprotection, and its disruption in the brain may lead to neurodegeneration $(45,46)$, suggesting that CREB exerts a pivotal role in neuroprotection. Therefore, the $\mathrm{ON}$ acupuncture treatment may have activated $\mathrm{GABA}_{\mathrm{B}}$ and increased the formation of cAMP in the brain, 

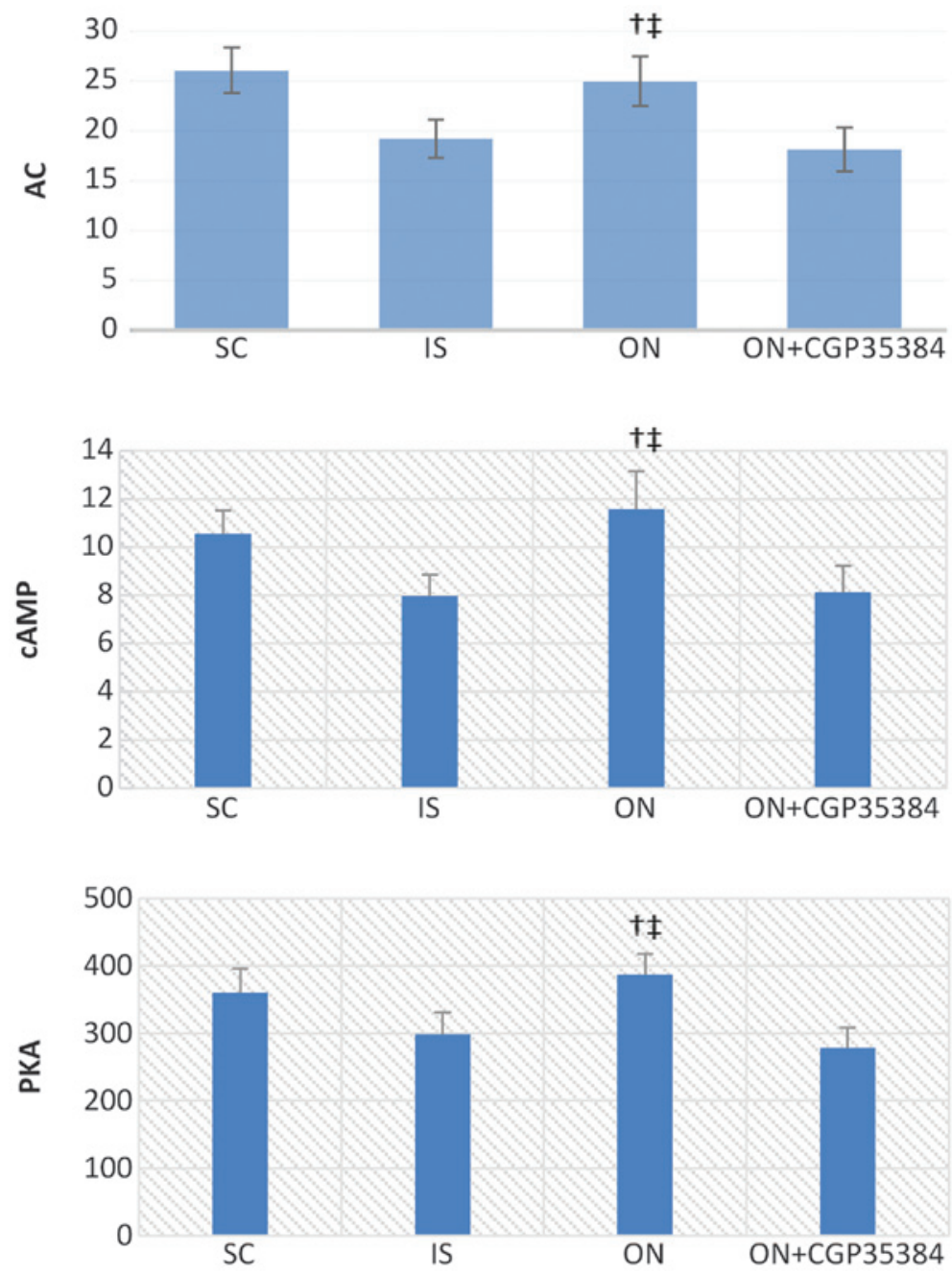

Figure 6. Protein expression levels of AC, cAMP and PKA in the serum. The serum levels of AC, cAMP and PKA were measured using ELISA. The data are presented as the mean \pm standard error of the mean. 'The ON group vs. the IS group, $\mathrm{P}<0.05$; the ON group vs. the ON + CGP 35384 group, $\mathrm{P}<0.05$. SC, sham-operation; IS, ischemia; ON, opposing needling; AC, adenylyl cyclase; PKA, protein kinase A.

which in turn activated PKA and led to the phosphorylation of CREB.

If the neuroprotection induced by $\mathrm{ON}$ is mediated through the cAMP/PKA/CREB signaling pathway, identifying the upstream target is of importance. The subsequent assays performed in the present study revealed that CREB phosphorylation increased following ON. Pretreatment with the $\mathrm{GABA}_{\mathrm{B}}$ antagonist, CGP35384, effectively inhibited the ON-induced activation of CREB. The neuroprotective effects induced by $\mathrm{ON}$ were also effectively inhibited by the $\mathrm{GABA}_{\mathrm{B}}$ antagonist, thereby indicating that the $\mathrm{GABA}_{\mathrm{B}}$ receptor is involved in neuroprotection induced by $\mathrm{ON}$ acupuncture. Therefore, the protective effect of ON against ischemia, mediated by the cAMP/PKA/CREB signaling pathway, may be due to its action on the $\mathrm{GABA}_{\mathrm{B} 1}$ and $\mathrm{GABA}_{\mathrm{B} 2}$ receptors. The activation of the $\mathrm{GABA}_{\mathrm{B} 1}$ and $\mathrm{GABA}_{\mathrm{B} 2}$ receptors may lead to an increase in the levels of cAMP, which subsequently promoted the activity of PKA and the phosphorylation of CREB, thereby leading to neuroprotection and the promotion of motor function recovery in MACO rats.

$\mathrm{GABA}_{\mathrm{B}}$ may provide specific protective effects against cerebral ischemic damage, which may be associated with the inhibition of an excessive efflux of excitatory amino acids, an increase in the levels of inhibitory amino acids and a decrease in the $\mathrm{Ca}^{2+}$ level in the cortex. However, the present study has certain limitations. The present study was not concerned with monitoring the levels of excitatory amino acids, including glutamate. Furthermore, it is unknown whether the motor function recovery and the neuroprotective effects are associated with the concentration of GABA, and further studies are required to address these questions.

In conclusion, the results of the present study demonstrated that $\mathrm{ON}$ improved the motor function in transient MCAO rats and exerted neuroprotection against ischemia, and such effects may be mediated through the $\mathrm{GABA}_{\mathrm{B}}$ receptor-cAMP/PKA/CREB signal transduction pathway. These results may assist in furthering our understanding of the mechanisms underlying $\mathrm{ON}$, and in providing a theoretical basis for clinical rehabilitation.

\section{Acknowledgements}

The present study was supported by a grant from the National Natural Science Foundation of China (no. 81102628). 


\section{References}

1. Minino AM, Xu J and Kochanek KD: Deaths: preliminary data for 2008. Natl Vital Stat Rep 59: 1-52, 2008.

2. Xu J, Kochanek KD, Murphy SL and Arias E. Mortality in the United States, 2012. NCHS Data Brief 168: 1-8, 2012.

3. Go AS, Mozaffarian D, Roger VL, Benjamin EJ, Berry JD, Borden WB, Bravata DM, Dai S, Ford ES, Fox CS, et al: Heart disease and stroke statistics - 2013 update: A report from the American Heart Association. Circulation 127: e6-e245, 2013.

4. Prevalence and most common causes of disability among adults - United States, 2005. MMWR Morb Mortal Wkly Rep 58 421-426, 2009

5. Ovbiagele B, Goldstein LB, Higashida RT, Howard VJ, Johnston SC, Khavjou OA, Lackland DT, Lichtman JH, Mohl S, Sacco RL, et al: Forecasting the future of stroke in the United States: A policy statement from the American Heart Association and American Stroke Association. Stroke 44: 2361-2375, 2013.

6. Sun H, Zou X and Liu L. Epidemiological factors of stroke: A survey of the current status in china. J Stroke 15: 109-114, 2013.

7. Xu G, Zhang Z, Lv Q, Li Y, Ye R, Xiong Y, Jiang Y and Liu X: NSFC health research funding and burden of disease in China. PLoS One 9: e111458, 2014.

8. Liu L, Wang D, Wong KS and Wang Y: Stroke and stroke care in China: Huge burden, significant workload, and a national priority. Stroke 42: 3651-3654, 2011.

9. Towfighi A and Saver JL: Stroke declines from third to fourth leading cause of death in the United States: Historical perspective and challenges ahead. Stroke 42: 2351-2355, 2011

10. Sun Liuhe WY: Study on applied law of opposing needling. Zhongguo Zhenjiu 23: 540-542, 2003 (In Chinese).

11. Gangting L: Effects of opposing needling with large needle on rheoencephalogram, hemorheology and blood lipids in the patient of cerebral infarction. Zhongguo Zhenjiu 24: 701-703, 2004 (In Chinese).

12. Xiaohui Y: Clinical observation on post-stroke hemiplegic patients with the treatment of Ju-ci method's massage. Chin Arch Tradit Chin Med 25: 1741-1742, 2007 (In Chinese).

13. Rothman SM and Olney JW: Glutamate and the pathophysiology of hypoxic - ischemic brain damage. Ann Neurol 19: 105-111, 1986

14. Gillani Q, Iqbal S, Arfa F, Khakwani S, Akbar A, Ullah A, Ali $M$ and Iqbal F: Effect of GABAB receptor antagonist (CGP35348) on learning and memory in albino mice. ScientificWorldJournal 2014: 983651, 2014.

15. Bettler B and Tiao JY: Molecular diversity, trafficking and subcellular localization of GABAB receptors. Pharmacol Ther 110: 533-543, 2006.

16. Li CJ, Lu Y, Zhou M, Zong XG, Li C, Xu XL, Guo LJ and Lu Q: Activation of GABAB receptors ameliorates cognitive impairment via restoring the balance of $\mathrm{HCN} 1 / \mathrm{HCN} 2$ surface expression in the hippocampal CA1 area in rats with chronic cerebral hypoperfusion. Mol Neurobiol 50: 704-720, 2014.

17. Cryan JF and Slattery DA. GABAB receptors and depression. Current status. Adv Pharmacol 58: 427-451, 2010.

18. Cimarosti H, Kantamneni S and Henley JM: Ischaemia differentially regulates $\mathrm{GABA}(\mathrm{B})$ receptor subunits in organotypic hippocampal slice cultures. Neuropharmacology 56: 1088-1096, 2009.

19. Cheng CY, Su SY, Tang NY, Ho TY, Lo WY and Hsieh CL: Ferulic acid inhibits nitric oxide-induced apoptosis by enhancing GABA(B1) receptor expression in transient focal cerebral ischemia in rats. Acta Pharmacol Sin 31: 889-899, 2010.

20. Jiang Y, Yang S and Tao J: Exploration of neuroprotective mechanism of opposing needling on the ischemia-reperfusion injured rats. Chin J Rehab Med 29: 605-609, 2914 (In Chinese).

21. Bardutzky J, Shen Q, Henninger N, Bouley J, Duong TQ and Fisher M: Differences in ischemic lesion evolution in different rat strains using diffusion and perfusion imaging. Stroke 36: 2000-2005, 2005.

22. Longa EZ, Weinstein PR, Carlson S and Cummins R: Reversible middle cerebral artery occlusion without craniectomy in rats. Stroke 20: 84-91, 1989.

23. Lipsanen A and Jolkkonen J. Experimental approaches to study functional recovery following cerebral ischemia. Cell Mol Life Sci 68: 3007-3017, 2011

24. Bozkurt A, Deumens R, Scheffel J, O'Dey DM, Weis J, Joosten EA, Führmann T, Brook GA and Pallua N: CatWalk gait analysis in assessment of functional recovery after sciatic nerve injury. J Neurosci Methods 173: 91-98, 2008.

25. Deumens R, Jaken RJ, Marcus MA and Joosten EA: The CatWalk gait analysis in assessment of both dynamic and static gait changes after adult rat sciatic nerve resection. J Neurosci Methods 164: 120-130, 2007.
26. Encarnacion A, Horie N, Keren-Gill H, O'Dey DM, Weis J, Joosten EA, Führmann T, Brook GA and Pallua N: Long-term behavioral assessment of function in an experimental model for ischemic stroke. J Neurosci Methods 196: 247-257, 2011.

27. Balkaya M, Kröber J, Gertz K, Peruzzaro S and Endres M: Characterization of long-term functional outcome in a murine model of mild brain ischemia. J Neurosci Methods 213: 179-187, 2013.

28. Parkkinen S, Ortega FJ, Kuptsova K, Huttunen J, Tarkka I and Jolkkonen J: Gait impairment in a rat model of focal cerebral ischemia. Stroke Res Treat 2013: 410972, 2013.

29. Rasoulpanah M, Kharazmi F and Hatam M: Evaluation of GABA Receptors of Ventral Tegmental Area in Cardiovascular Responses in Rat. Iran J Med Sci 39: 374-381, 2014.

30. Li XL, Fan NX, Meng HZ, Shi MX, Luo D and Zhang NY: Specific neuroprotective effects of manual stimulation of real acupoints versus non-acupoints in rats after middle cerebral artery occlusion. Afr J Tradit Complement Altern Med 10: 186-195, 2013.

31. O'Donnell ME, Chen YJ, Lam TI, Taylor KC, Walton JH and Anderson SE: Intravenous HOE-642 reduces brain edema and $\mathrm{Na}$ uptake in the rat permanent middle cerebral artery occlusion model of stroke: Evidence for participation of the blood-brain barrier $\mathrm{Na} / \mathrm{H}$ exchanger. J Cereb Blood Flow Metab 33: 225-234, 2013.

32. Luo D, Fan X, Ma C, Fan T, Wang X, Chang N, Li L, Zhang Y, Meng Z, Wang S and Shi X: A Study on the Effect of Neurogenesis and Regulation of GSK3beta/PP2A Expression in Acupuncture Treatment of Neural Functional Damage Caused by Focal Ischemia in MCAO Rats. Evid Based Complement Alternat Med 2014,p. 962343, 2014.

33. Chen A: The mechanism of electroacupuncture for cerebral ischemia reperfusion injury by means of PI3K/AKT signal transduction pathway Master's thesis, Fujian TCM University, 2013.

34. Livak KJ and Schmittgen TD: Analysis of relative gene expression data using real-time quantitative PCR and the 2(-Delta Delta C(T)) Method. Methods 25: 402-408, 2001.

35. Du Y, Yan L, Wang J,Zhan W, Song K, Han X, Li X, Cao J and Liu H: 31-Adrenoceptor autoantibodies from DCM patients enhance the proliferation of T lymphocytes through the $\beta 1$-AR-cAMP/PKA and p38 MAPK pathways. PLoS One 7: e52911, 2012.

36. Choi DW: Glutamate neurotoxicity in cortical cell culture is calcium dependent. Neurosci Lett 58: 293-297, 1985.

37. Smith WS: Pathophysiology of focal cerebral ischemia: a therapeutic perspective. J Vasc Interv Radiol 15: S3-S12, 2004.

38. Ouyang C, Guo L, Lu Q and Qu L: Effects of $\gamma$-aminobutyric acid on amino acids and calcium levels in rat brain of acute incomplete global cerebral ischemia. Chin J Pharmacol Toxicol 18: 248-252, 2004

39. Nelson RM, Hainsworth AH, Lambert DG, Jones JA, Murray TK, Richards DA, Gabrielsson J, Cross AJ and Green AR: Neuroprotective efficacy of AR-A008055, a clomethiazole analogue, in a global model of acute ischaemic stroke and its effect on ischaemia-induced glutamate and GABA efflux in vitro. Neuropharmacology 41: 159-166, 2001.

40. Dave KR, Lange-Asschenfeldt C, Raval AP, Prado R, Busto R, Saul I and Pérez-Pinzón MA: Ischemic preconditioning ameliorates excitotoxicity by shifting glutamate/gamma-aminobutyric acid release and biosynthesis. J Neurosci Res 82: 665-673, 2005.

41. Takeo S, Niimura M, Miyake-Takagi K, Nagakura A, Fukatsu T, Ando T, Takagi N, Tanonaka K and Hara J: A possible mechanism for improvement by a cognition-enhancer nefiracetam of spatial memory function and cAMP-mediated signal transduction system in sustained cerebral ischaemia in rats. Br J Pharmacol 138: 642-654, 2003.

42. Wu W, Yu X, Luo XP, Yang SH and Zheng D: Tetramethylpyrazine protects against scopolamine-induced memory impairments in rats by reversing the CAMP/PKA/CREB pathway. Behav Brain Res 253: 212-216, 2013.

43. Nu LC, Zhang YH, Li CQ, Liu B, Jiang Y and Li LL: Effects of rehabilitation training on motor function recovery and cAMP-PKA signal transduction pathway after ischemic stroke in rats. Acta Laboratorium Animalis Scientia Sinica 21 doi:10.3969/j.issn.1005-4847.2014.03.000, 2014

44. Bowery NG, Bettler B, Froestl W, Gallagher JP, Marshall F, Raiteri M, Bonner TI and Enna SJ: International Union of Pharmacology. XXXIII. Mammalian gamma-aminobutyric acid(B) receptors: Structure and Function. Pharmacol Rev 54: 247-264, 2002.

45. Dawson TM and Ginty DD: CREB family transcription factors inhibit neuronal suicide. Nat Med 8: 450-451, 2002.

46. Ao H, Ko SW and Zhuo M. CREB activity maintains the survival of cingulate cortical pyramidal neurons in the adult mouse brain. Mol Pain 2: 15, 2006. 